\title{
O projeto "lançamento de projéteis": uma perspectiva para o ensino e aprendizagem da matemática no ensino médio
}

\author{
The project "projectiles launch ": a perspective for teaching and learning math in high \\ school
}

\author{
Valmir Ninow \\ vninow@gmail.com \\ Carmen Teresa Kaiber \\ carmen_kaiber@hotmail.com
}

\begin{abstract}
Resumo
Este artigo apresenta resultados do projeto Lançamento de Projéteis, desenvolvido por um grupo de estudantes do terceiro ano do Ensino Médio, no âmbito de uma pesquisa cujo objetivo foi investigar o desenvolvimento de Projetos de Trabalho, considerando diferentes estratégias, procedimentos e recursos, visando à construção de conhecimentos matemáticos. O trabalho possibilitou a retomada e desenvolvimento de conhecimentos relacionados às áreas de Matemática e Física, sendo que, particularmente, foram desenvolvidos aspectos referentes às Funções Afim e Quadrática, Movimento Retilíneo Uniforme e Uniformemente Variado e do Lançamento Oblíquo. Para tal, foram utilizados elementos advindos da Modelagem Matemática, bem como utilizado o software Excel para construir, modelar e analisar as situações que se apresentaram. O trabalho constituiu-se, também, em possibilidade de modificação do papel do professor e dos estudantes, permitindo a esses tornarem-se atuantes e participativos, a partir de ações que envolveram trabalho em grupo, organização, planejamento, pesquisa e o enfrentamento e solução de situações tanto práticas quanto teóricas.
\end{abstract}

Palavras-chave: Projetos de trabalho; Modelagem matemática; Lançamento oblíquo.

\begin{abstract}
This article presents project results Projectiles Launch, in the context of research aimed to investigate the development of Work Projects, considering different strategies, procedures and resources, to the construction of mathematical knowledge. The work enabled a return and development of knowledge related to the areas of Mathematics and Physics, and, particularly, aspects were developed relating to Affine and Quadratic Functions, Rectilinear Motion, Miscellaneous Uniform Rectilinear Motion and Oblique Launch. For such elements were used coming from the Mathematical Modeling as well as utilized the Excel software to build, model and analyze the situations that presented themselves. The work consisted also in the possibility of changing the role of teacher and students, allowing these become active and participative, from actions involving group work, organization, planning, research and confrontation and solving situations both practical and theoretical.
\end{abstract}

Keywords: Work projects; Math modeling; Oblique launch.

\section{Introdução}

Os processos de ensino e aprendizagem da Matemática, bem como as dificuldades encontradas pelos estudantes na apropriação de ideias, conceitos e procedimentos próprios da disciplina têm sido foco de investigações no âmbito da Educação Matemática.

Buscando apontar caminhos que possam qualificar o processo de ensino e aprendizagem da Matemática, encontram-se nos Projetos de Trabalho (MALHEIROS, 2008; 
MORA, 2003; HERNÁNDEZ, 1998 e HERNÁNDEZ e VENTURA, 1998) possibilidades do desenvolvimento não só de conhecimentos conceituais matemáticos, mas também, dos chamados conteúdos procedimentais e atitudinais (COLL,1996). Os Projetos de Trabalho, na visão de Hernández e Ventura (1998), buscam vincular o que se aprende na escola com as preocupações dos alunos referentes às questões fora do ambiente escolar, no âmbito cultural, social, político, econômico, o que pode possibilitar um trabalho rico em situações e contextos onde a Matemática possa ser utilizada e desenvolvida.

No âmbito dos Projetos de Trabalho, conjectura-se sobre a possível utilização e articulação de estratégias e procedimentos os quais envolvam a Modelagem Matemática e as Tecnologias Digitais como possibilidade de intervenção na escola, permitindo aos estudantes desenvolverem atividades exploratórias, realizarem descobertas por eles próprios e construírem conceitos, tal como é preconizado por pesquisadores como Malheiros (2008), Ripardo, Oliveira e Silva (2009), Bassanezi (2002), entre outros.

Nesse contexto, o trabalho aqui apresentado é parte de uma pesquisa que teve por objetivo investigar o desenvolvimento de Projetos de Trabalho que integrem diferentes estratégias, procedimentos e recursos visando à construção de conhecimentos matemáticos, junto a estudantes de um terceiro ano do Ensino Médio de uma escola da rede estadual de educação localizada no município de Farroupilha, Rio Grande do Sul.

No âmbito do trabalho realizado, destaca-se o projeto "Lançamento de Projéteis" o qual visou à retomada e desenvolvimento de temas relacionados às Funções Afim e Quadrática, Movimento Retilíneo Uniforme e Uniformemente Variado e do Lançamento Oblíquo no contexto do que os estudantes envolvidos denominaram "aprofundar conhecimentos em Matemática e Física”. O projeto contou com a utilização de elementos advindos da Modelagem Matemática, bem como das Tecnologias Digitais, a partir da utilização do software Excel para construir, modelar e analisar as situações em estudo.

\section{Projetos de Trabalho e Modelagem Matemática: uma possível articulação}

Os Projetos de Trabalho buscam estabelecer uma ligação entre teoria e prática, introduzindo uma proposta de mudança na organização curricular da escola. A busca é pela possibilidade do conhecimento tornar-se significativo ao aluno, quando esse faz conexões com a realidade, com aquilo que já sabe sobre a questão em estudo, com suas referências internas e externas, as quais, por meio do diálogo e questionamentos entre professor e aluno, se construirão adequadamente num processo de ensino e aprendizagem (HERNÁNDEZ e VENTURA, 1998). Apontam outra maneira de construir o conhecimento escolar, baseado na 
interpretação da realidade, e orientado para o estabelecimento de relações entre a vida dos estudantes, professores e o conhecimento advindo das disciplinas e de outros saberes não disciplinares (HERNÁNDEZ, 1998).

Já a Modelagem Matemática, na visão de Bassanezi (2002), consiste na arte de transformar problemas da realidade e resolvê-los, interpretando suas soluções na linguagem do mundo real, ou seja, é o estudo de situações ou problemas reais usando a Matemática para sua compreensão, simplificação e resolução. Para o autor, o modelo matemático pode ser uma das possíveis representações ou a interpretação de parte de uma realidade ou da realidade sendo que, na tentativa de compreender essa realidade, o indivíduo busca meios para atingi-la e transformá-la.

Groenwald, Silva e Mora (2004) ponderam que essas tendências educacionais estão, muitas vezes, relacionadas e podem ser aplicadas, de modo articulado, durante o desenvolvimento de atividades de ensino e aprendizagem ao longo do ano escolar. Apontam que, de modo geral, as mesmas apresentam pontos em comum, dos quais se podem destacar:

- um ensino comprometido com as transformações sociais e a construção da cidadania;

- desenvolvimento contando com a participação ativa do aluno no processo de ensino e aprendizagem em um contexto de trabalho em grupo e não individual;

- a busca de uma Matemática significativa para o aluno, vinculando-a a realidade;

- utilização de recursos específicos e um ambiente que propicie o desenvolvimento de sequências metodológicas que levem o aluno a construir seu próprio conhecimento (GROENWALD; SILVA; MORA, 2004, p. 43).

Nessa mesma linha de pensamento, as Orientações Curriculares Nacionais para o Ensino Médio, apontam que,

\begin{abstract}
[...] articulada com a ideia de modelagem matemática tem-se a alternativa de trabalho com projetos. Um projeto pode favorecer a criação de estratégias de organização dos conhecimentos escolares, ao integrar os diferentes saberes disciplinares. Ele pode iniciar a partir de um problema bem particular ou de algo mais geral, de uma temática ou de um conjunto de questões inter-relacionadas. Mas, antes de tudo, deve ter como prioridade o estudo de um tema que seja de interesse dos alunos, de forma que se promova a interação social e a reflexão sobre problemas que fazem parte da sua realidade (BRASIL, 2006, p. 85).
\end{abstract}

Ripardo, Oliveira e Silva (2009) consideram que essas articulações vão além dos limites curriculares e implicam na realização de atividades práticas, onde os temas selecionados são apropriados aos interesses e ao estágio de desenvolvimento dos alunos. Implicam, também, na realização de experiências e de pesquisas, necessitando, assim, de estratégias de busca, organização e estudo de fontes de informação, em atividades individuais e de grupo, além de se levar em consideração as diferentes habilidades e conceitos que são apreendidos. Os autores destacam que uma das vantagens desse tipo de articulação em atividades de ensino, diz respeito à possibilidade de se utilizar o contexto de vida dos alunos, 
ou seus interesses, como o marco inicial para a abordagem ou aprofundamento de um conteúdo específico. Porém, ponderam que não podem ser aplicadas como recursos metodológicos em todos os conteúdos de uma disciplina ou em todos os problemas de uma escola.

Malheiros (2011) salienta que a interação entre essas propostas ocorre apenas quando o tema eleito para a investigação surge do interesse dos alunos ou quando esse é definido a partir de uma negociação pedagógica na qual os estudantes têm voz, são ouvidos e seus interesses prevalecem. Relata, também,

[...] que as características apresentadas nos Projetos podem ser relacionadas à Modelagem, no contexto educacional, quando um estudante, ou grupo deles, escolhe um tema para pesquisar, além do interesse subentendido, eles têm um objetivo, uma meta a ser alcançada e, na maioria das vezes, há predições e referências ao futuro. Além disso, existe a vontade da descoberta, de saber mais sobre aquilo que está sendo investigado. E, assim como na utilização de Projetos em sala de aula, também não existem certezas na Modelagem (MALHEIROS, 2011, p. 80).

Ainda, conforme Malheiros (2008), elementos como interesse, existência de objetivos e metas, predições e referência ao futuro, a vontade da descoberta, a inexistência de certezas, a singularidade, a não-valorização excessiva dos fins a serem atingidos, dentre outros presentes na literatura sobre projetos, podem ser encontrados na Modelagem.

No que se refere à organização do trabalho com Projetos, para o desenvolvimento junto aos estudantes, optou-se por seguir as orientações apontadas por Mora (2003), pois se entende que, em sua perspectiva, o autor apresenta uma síntese completa das principais características de um Projeto de Trabalho.

Para o autor o desenvolvimento de um projeto apresenta cinco fases, as quais são apresentadas e descritas no quadro da Figura 1.

Figura 1: Fases do desenvolvimento de Projetos de Trabalho

\begin{tabular}{|c|c|l|}
\hline FASES & DESCRIÇÃO & \multicolumn{1}{c|}{ CARACTERÍSTICAS } \\
\hline Fase I & Definição dos temas. & Devem ser relevantes e de interesse dos alunos. \\
\hline Fase II & Discussão e planejamento. & $\begin{array}{l}\text { Discussão entre alunos e professores sobre a possibilidade } \\
\text { de realização e planejamento das atividades. }\end{array}$ \\
\hline Fase III & $\begin{array}{c}\text { Organização das ações a serem } \\
\text { realizadas. }\end{array}$ & $\begin{array}{l}\text { São estabelecidas as ações, os prazos, a bibliografia e os } \\
\text { recursos materiais, humanos e técnicos. }\end{array}$ \\
\hline Fase IV & $\begin{array}{l}\text { Dealização da pesquisa (planejar, elaborar, produzir) e } \\
\text { perificação dos processos (re-planejar, re-elaborar, re- } \\
\text { produzir). }\end{array}$ \\
\hline Fase V & Finalização dos projetos. & $\begin{array}{l}\text { Socialização dos resultados, discussão dos projetos } \\
\text { apresentados, reformulação dos projetos entrega de } \\
\text { relatório final. }\end{array}$ \\
\hline
\end{tabular}

Fonte: adaptado de Mora (2003).

Com relação a avaliação no âmbito de um projeto, Mora (2003) destaca que é necessário considerar tanto a avaliação do processo e do produto, correspondente ao 
desenvolvimento global do projeto, como a avaliação dos estudantes, considerando sua participação e rendimento individual e coletivo durante todas as fases.

Para o autor, o produto de um projeto se qualifica tanto do ponto de vista individual como no de grupo, pois entra em jogo um conjunto de componentes subjetivos muito importantes, tais como sentimento de orgulho, comprometimento, companheirismo, além de uma série de habilidades e atitudes muitas vezes não quantificáveis individualmente. Pondera, ainda, que a avaliação se completa com a qualificação contínua do processo, de maneira coletiva, pois cada fase do projeto necessita de momentos de avaliação que têm por finalidade dar continuidade à fase seguinte. Ocorrem dessa forma, duas avaliações simultâneas: a avaliação temporal do projeto e a avaliação do coletivo em sua realização (MORA, 2003). Conforme o autor, a prática educativa centrada nos Projetos de Trabalho permite apreciar as contribuições e o desenvolvimento da conduta de aprendizagem dos participantes, sendo que a avaliação, tanto dos alunos quanto do projeto, depende de variáveis como idade, duração, tema de investigação e as características do projeto.

Assume-se, portanto, a ideia de que os Projetos de Trabalho possibilitam o desenvolvimento de temas de interesse dos estudantes, constituindo-se em um espaço para o ensino e aprendizagem, não só de conteúdos específicos, mas, também, de procedimentos, valores e princípios. Possibilitam, também, o desenvolvimento de um trabalho colaborativo entre os participantes, no qual os estudantes assumem a responsabilidade pela sua aprendizagem e o professor pode atuar como um orientador que investiga e compartilha conhecimentos.

\section{O Trabalho Desenvolvido: Aspectos Metodológicos}

O projeto "Lançamento de Projéteis" foi desenvolvido por um grupo de quatro alunos da turma 302 do terceiro ano do Ensino Médio do Colégio do Colégio Estadual Farroupilha, em Farroupilha/RS, Brasil, como parte integrante de uma pesquisa de mestrado cujo objetivo foi investigar o desenvolvimento de Projetos de Trabalho que integrassem diferentes estratégias, procedimentos e recursos visando à construção de conhecimentos matemáticos juntos a estudantes desse nível de ensino. Além do projeto aqui apresentado, foram desenvolvidos outros oito projetos envolvendo todos os estudantes da referida turma.

Optou-se por uma investigação de base qualitativa que, segundo Bogdan e Biklen (1994), se caracteriza por ter o ambiente natural como fonte direta de dados e o pesquisador como seu principal instrumento, a predominância de dados descritivos e as análises tendendo a seguir um processo indutivo. Os autores apontam, ainda, que nesse tipo de pesquisa o 
processo é mais importante que o produto, sendo que o destaque é para o significado que os envolvidos atribuem às coisas.

Nesse contexto, os procedimentos e instrumentos adotados pelo professor/pesquisador para a coleta de dados e análise das atividades desenvolvidas contaram com a observação participante e registro em diário de campo, gravações em áudio e vídeo, fotos das atividades realizadas, análise dos registros da produção dos estudantes, a partir das atividades do projeto, redação do relatório final e apresentações dos trabalhos.

\section{O Projeto Lançamento de Projéteis}

O projeto desenvolvido pelo denominado Grupo-A, foi elaborado seguindo as fases propostas por Mora (2003) já destacadas, as quais passam a ser descritas e analisadas.

Na primeira fase, o Grupo-A definiu o tema do projeto, a partir de discussões e da curiosidade em relação ao lançamento de projéteis, advinda de estudos realizados no ano anterior, pelos componentes do grupo, sobre o Movimento Retilíneo Uniforme e o Uniformemente Variado e pelo fato de não ter sido realizado um estudo aprofundado sobre o Lançamento Oblíquo, nem a realização de aplicações práticas sobre o tema.

Destaca-se que a opção do grupo por trabalhar com questões intrínsecas a Física e a Matemática surpreendeu o professor, uma vez que nos primeiros contatos sobre o trabalho a ser desenvolvido foi destacado, com ênfase, que as propostas poderiam se relacionar com qualquer tema ou questão que fosse do interesse dos mesmos. Após a apresentação por escrito do tema, o professor/pesquisador se reuniu com o grupo de estudantes para discutir a viabilidade do desenvolvimento do projeto com o tema proposto e estabelecer os objetivos. Assim, o grupo definiu que o objetivo era "analisar o lançamento de projéteis na perspectiva da Física e da Matemática”.

$\mathrm{Na}$ segunda fase, os estudantes realizaram o planejamento, estabelecendo as ações necessárias para alcançar o objetivo proposto, as quais são apresentadas na Figura 2.

Figura 2: Planejamento do Grupo-A.

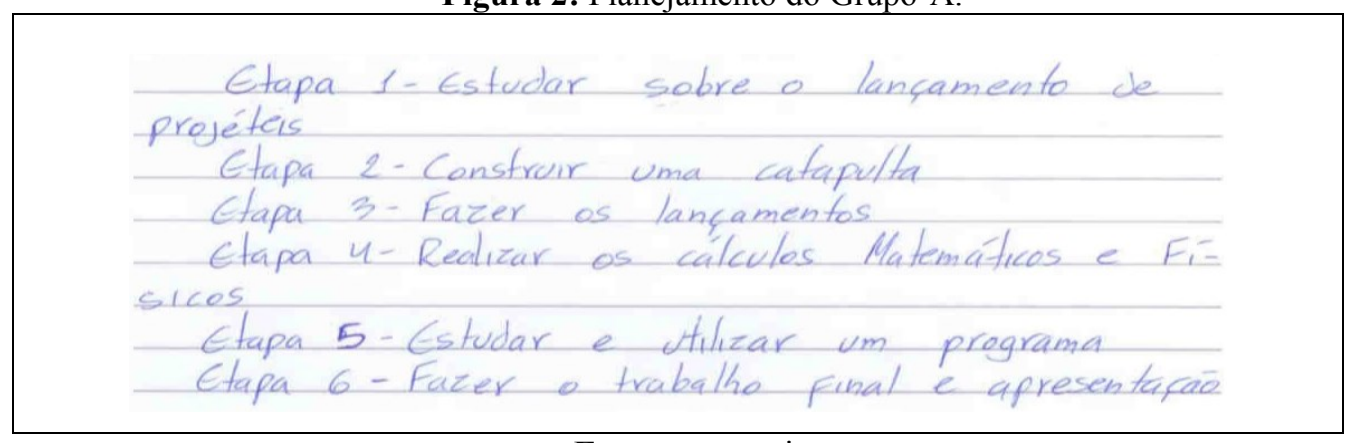

Fonte: a pesquisa. 
Os estudantes optaram por um planejamento inicial a partir de etapas a serem cumpridas semanalmente e estabeleceram, em uma terceira fase, um cronograma com as ações a serem desenvolvidas. As etapas abrangeram desde pesquisas e estudo sobre lançamento de projéteis, passando pela construção de uma catapulta, realização dos experimentos para coleta de dados e do processo de busca por relações matemáticas referentes aos mesmos. Fez parte do planejamento, também, o estudo e utilização de um software que auxiliasse no desenvolvimento do trabalho. Ao final, o objetivo era de produzir um relatório e uma apresentação do trabalho para toda a turma, como forma de socializar o realizado.

Dando sequência ao desenvolvimento do projeto, na quarta fase, os estudantes iniciaram a construção do esboço do desenho de uma catapulta do tipo Trebuchet $^{1}$ e, posteriormente, a construíram (Figura 3). O grupo seguiu, basicamente, um modelo criado por um grupo de estudantes de engenharia e que está disponível no Youtube ${ }^{2}$ utilizando-se, também, de outras informações obtidas nas pesquisas realizadas.

Figura 3: Catapulta criada pelo Grupo-A

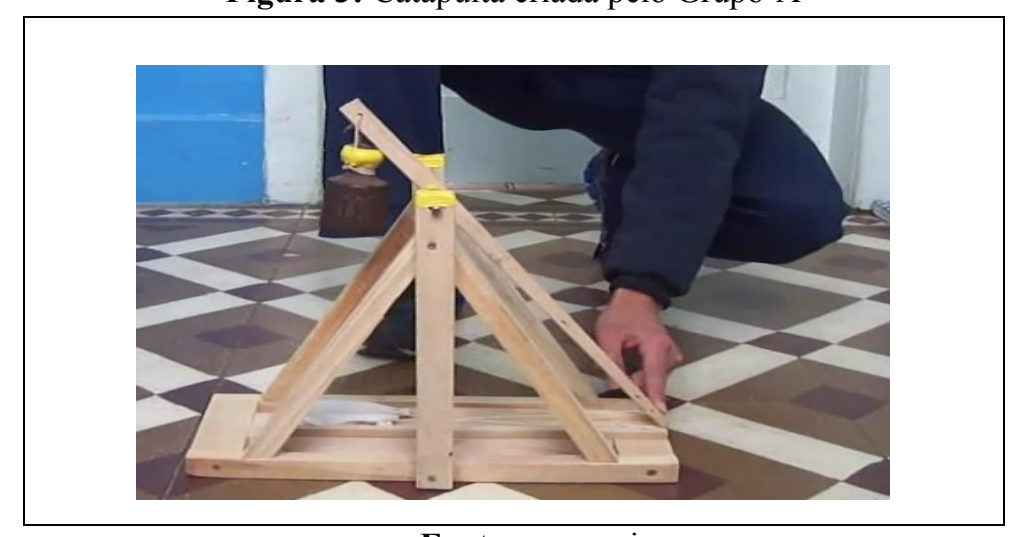

Fonte: a pesquisa.

Além do apoio e orientação do professor/pesquisador, os estudantes tiveram auxílio dos professores de Física da Escola. Os alunos se esforçaram no estudo e pesquisa buscando em livros didáticos e em outros materiais, bem como junto aos professores, tanto o entendimento teórico quanto os modelos os quais estariam relacionados ao trabalho. Nesse processo, retomaram as equações do Movimento Retilíneo Uniforme (MRU) e do Movimento Retilíneo Uniformemente Variado (MRUV), já conhecidas, buscando adequá-las ao lançamento oblíquo envolvido na atividade, o que pode ser visto na Figura 4.

\footnotetext{
${ }^{1}$ A Trebuchet é uma catapulta que foi utilizada como instrumento de guerra, na Europa, durante o período Medieval e usa um contrapeso de grande massa para arremessar projéteis ligados à extremidade oposta (WIKIPÉDIA, 2014).

${ }^{2}$ http://www.youtube.com/watch?v=Q- X81LPVwo. Acesso em: 10 de junho de 2013.
} 
Figura 4: Equações para a posição do projétil em relação aos eixos x e y.

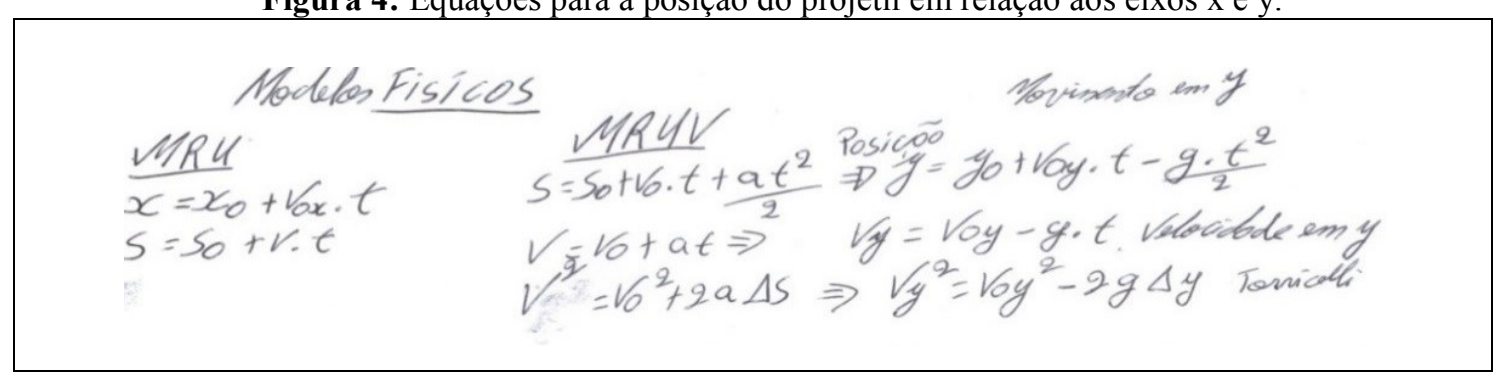

Fonte: a pesquisa.

Após esses primeiros estudos, os alunos buscaram a elaboração de outras equações, tais como: alcance máximo do móvel a partir do lançamento, altura máxima atingida e o tempo para o objeto atingir essa altura máxima.

Ao termino dessa atividade teórica e com a catapulta pronta, os estudantes, juntamente com um dos professores de Física, já bastante envolvido com o trabalho, realizaram lançamentos com dois pesos, um de 10 gramas e outro de 20 gramas, sendo que, para cada peso foram realizados 15 lançamentos. Para fazer as medições referentes a esses lançamentos, foi tomada como referência uma parede de tijolos à vista e, após cada lançamento, as devidas marcações e medições eram realizadas. Para a medição do tempo foi utilizado um cronômetro.

Por fim, os estudantes optaram por trabalhar com os dados referentes ao peso de $20 \mathrm{~g}$, calculando uma média para cada uma das grandezas envolvidas, estabelecendo os valores que foram utilizados, posteriormente, nos cálculos realizados (altura média $=2,57 \mathrm{~m}$; distância média $=7,60 \mathrm{~m}$; tempo médio=1,3986s). Os dados referentes as medias das medições obtidas nos lançamentos foram organizadas em três partes, de acordo com as variáveis envolvidas: distância $\mathrm{x}$ altura, altura $\mathrm{x}$ tempo e distância $\mathrm{x}$ tempo, como pode ser visto na Figura 5, separando, dessa forma, o movimento do projétil em três situações diferentes para ser analisado e interpretado.

Figura 5: Tabelas com as variáveis envolvidas no lançamento com o peso de $20 \mathrm{~g}$.

\begin{tabular}{|c|c|c|c|c|c|}
\hline \multicolumn{2}{|c|}{ distanciax sltena } & \multicolumn{2}{|c|}{ tempox Altma } & \multicolumn{2}{|c|}{ tempo 1 distancic } \\
\hline$d(m)$ & $h(m)$ & $f(1)$ & $h(\mathrm{~m})$ & $f(2)$ & $d(m)$ \\
\hline 0 & 0 & 0 & 0 & 0 & 0 \\
\hline 3,8 & 2,57 & 0,695 & 2,57 & 0,645 & 3,8 \\
\hline 7,6 & 0 & 1,39 & 0 & 2,39 & 76 \\
\hline
\end{tabular}

Fonte: a pesquisa.

Com esses valores, primeiramente, foram construídos os respectivos gráficos (Figura 6) e analisadas as principais características, como domínio, conjunto imagem, tipo de gráfico, se representava uma função de primeiro ou segundo grau, entre outros. 
Figura 6: Gráficos referentes aos dados apresentados na Figura 5.

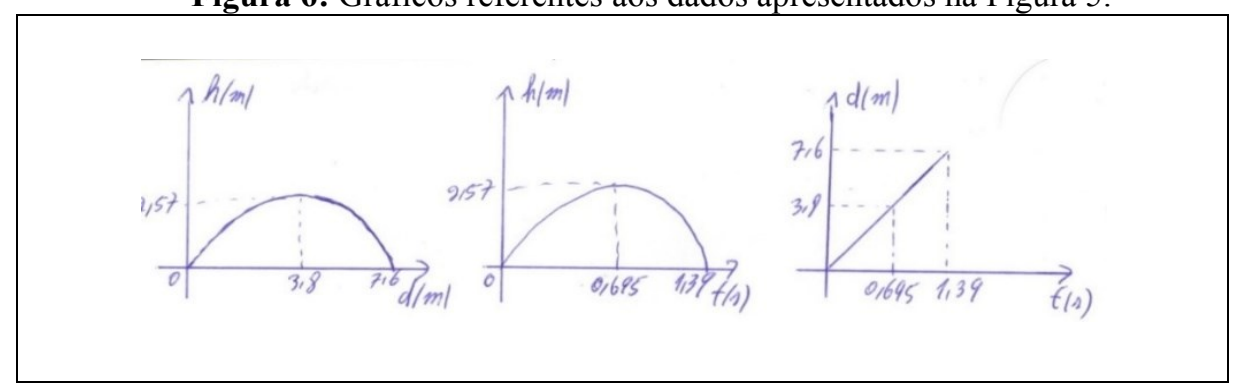

Fonte: a pesquisa.

$\mathrm{Na}$ realização dessas tarefas os alunos não apresentaram dúvidas e souberam utilizar de forma adequada conhecimentos sobre funções, para tabelar, construir gráficos e fazer a análise dos mesmos.

Na sequência, iniciaram os cálculos com os valores das variáveis acima apresentadas, buscando encontrar uma expressão matemática que descrevesse a situação estudada, sendo que, para essa tarefa, utilizaram-se do modelo $y=a x^{2}+b x+c$. Na Figura 7 destacam-se as equações obtidas bem como, novamente, a representação gráfica da situação.

Figura 7: Cálculos realizados para estabelecer as expressões matemáticas.

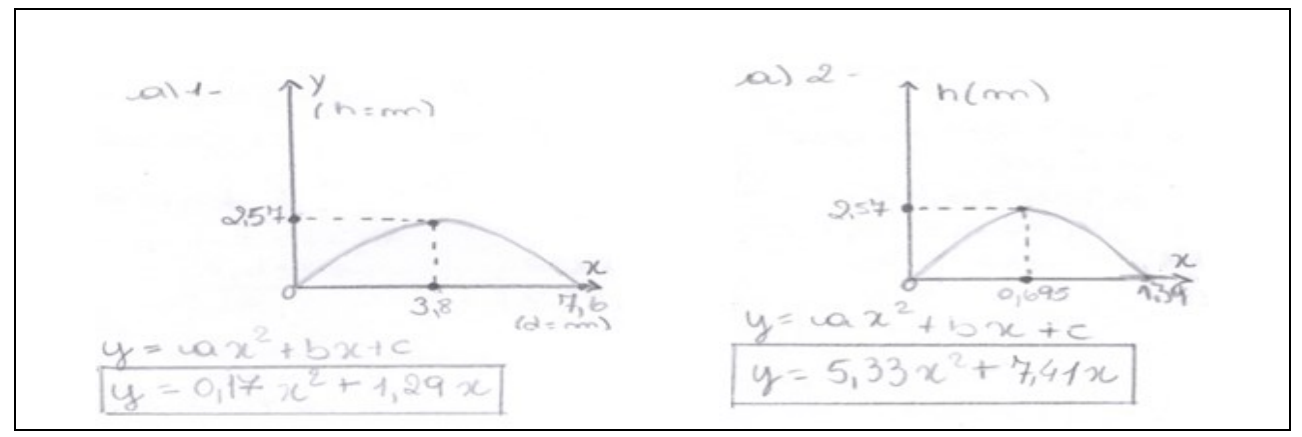

Fonte: a pesquisa.

Contudo, foi possível perceber que os estudantes não chegaram à forma correta das funções quadráticas referentes aos lançamentos, representando-as como sendo

$$
y=0,17 x^{2}+1,29 \text { e } y=5,33 x^{2}+7,41 x .
$$

No caso, as representações geométricas foram construídas a partir dos dados experimentais, o que resultou em curvas com a concavidade voltada para baixo. Assim as expressões algébricas representantes dessas curvas deveriam apresentar o sinal do coeficiente $a$ negativo. Essas divergências foram questionadas pelo professor, seguido de ampla discussão e reformulação. Ressalta-se, aqui, a responsabilidade do professor em acompanhar os trabalhos no sentido de questionar e problematizar as situações, e os possíveis erros, como possibilidade dos estudantes confrontarem-se com inconsistências, erros e equívocos, analisando, argumentando e, se necessário, reformulando. 
Já referente ao terceiro gráfico apresentado na Figura 6, o qual se relaciona a uma função do primeiro grau, os estudantes utilizaram a equação geral que define a lei de formação chegando em

$$
y=5,46 x+0,01
$$

a qual descreve a relação entre a distância e o tempo. Os cálculos referentes a essa formulação são apresentados na Figura 8.

Figura 8: Cálculos realizados para encontrar a função $y=5,46 x+0,01$.

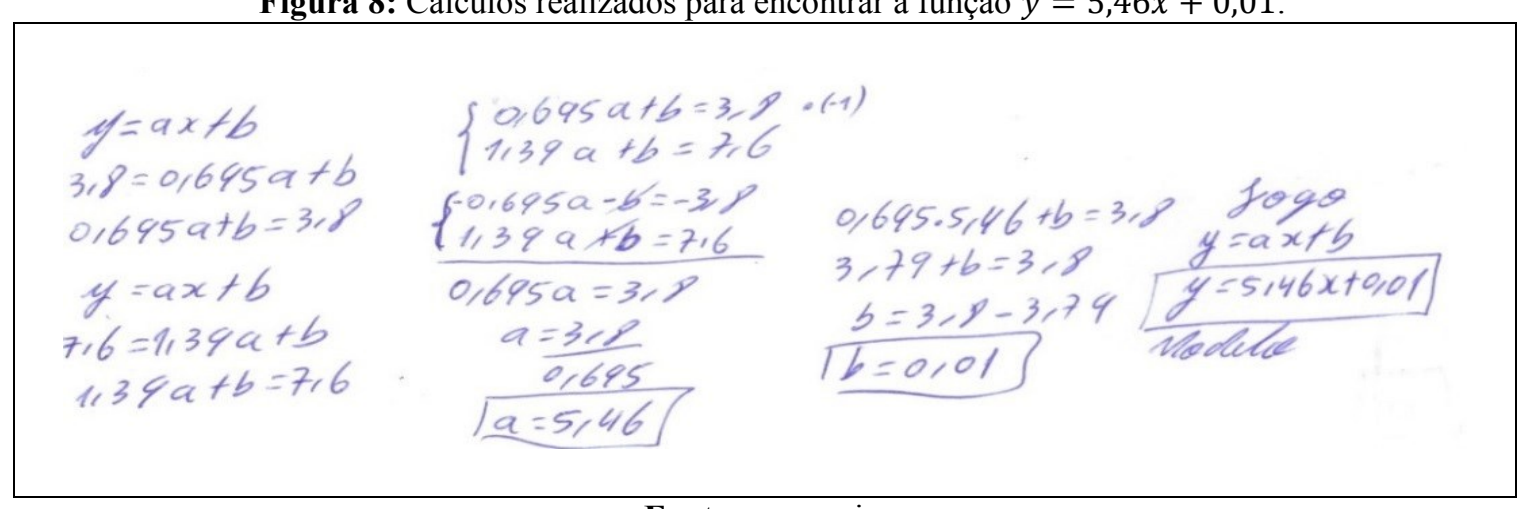

Fonte: a pesquisa.

Observando-se a resolução dessa atividade, um fato que chama a atenção é o valor encontrado para o coeficiente $b(b=0,01)$. Como os estudantes tomaram como referência a origem do plano cartesiano, ponto $\mathrm{P}(0,0)$, o valor numérico de $b$ deveria ser zero. Essa questão foi problematizada e discutida, e os estudantes justificaram a diferença considerando possíveis erros cometidos durante a realização dos testes, na tomada de medidas e nos arredondamentos realizados anteriormente.

Porém, uma questão surgiu logo nos primeiros experimentos. Como em uma catapulta um dos princípios básicos é variar o ângulo de lançamento, a fim de que um determinado alvo, uma distância ou uma altura seja atingido, o modelo físico criado pelo grupo apresentava uma grande limitação, pois não permitia fazer as devidas variações referentes ao ângulo de lançamento que se mantinha o mesmo, aspecto que não havia sido considerado quando da construção da catapulta. Como solução o grupo apresentou a ideia de que a mudança deveria ocorrer no peso a ser lançado, e no contrapeso, para que ocorressem variações na trajetória do móvel.

Após a conclusão dessa etapa, o professor/pesquisador se reuniu com os estudantes para discutir o modelo de catapulta criado e possíveis alternativas para o problema relacionado ao ângulo de inclinação de lançamento. Questionados sobre a possibilidade de fazer modificações na catapulta, incorporando a ideia de alteração nos pesos, o grupo salientou que não saberiam como fazer essas adaptações, e que de todo modo a ideia poderia alterar o princípio da catapulta. 
Buscando uma alternativa para a questão, o professor/pesquisador sugeriu desenvolver outro lançador de projéteis, a partir de um protótipo de foguete de garrafa PET, água e ar comprimido, desenvolvido por um grupo de estudantes de Engenharia da Unisal de Lorena, São Paulo. Após assistir a um vídeo sobre o tema ${ }^{3}$ e discutir a ideia e possibilidades de colocá-la em prática, o grupo aceitou o desafio de fazer experiências com um novo lançador de projéteis, buscando uma análise das mudanças no deslocamento do projétil, de acordo com as variações nos ângulos de lançamento. Por fim, o professor disponibilizou vídeos e materiais no grupo do Fecebook e solicitou que fossem pesquisadas outras opções para o novo lançador de projétil.

Com relação ao grupo do Facebook mencionado, destaca-se que fez parte do desenvolvimento dos projetos a utilização do Facebook como canal de comunicação entre os componentes de cada grupo e o professor. Assim, foi possível estender a interação para além da sala de aula ou encontros fora do período normal das aulas. Esse canal de comunicação foi bastante utilizado tanto pelo professor, com a disponibilização de materiais e contato permanente com os estudantes, como entre os componentes do grupo que, em diversos momentos, mantiveram discussões sobre questões do projeto.

\section{O lançador de projéteis de garrafa PET}

Para a construção do lançador de garrafa PET, os estudantes utilizaram madeira, pedaços de cano, luvas, joelhos em PVC, entre outros. Para o projétil, foram utilizadas garrafas, fita, papelão e cola. Já para o lançamento foram utilizadas uma bombinha de ar comprimido e água. A construção realizada pelos estudantes pode ser vista na Figura 9.

Figura 9: Lançador de foguete de garrafa PET.

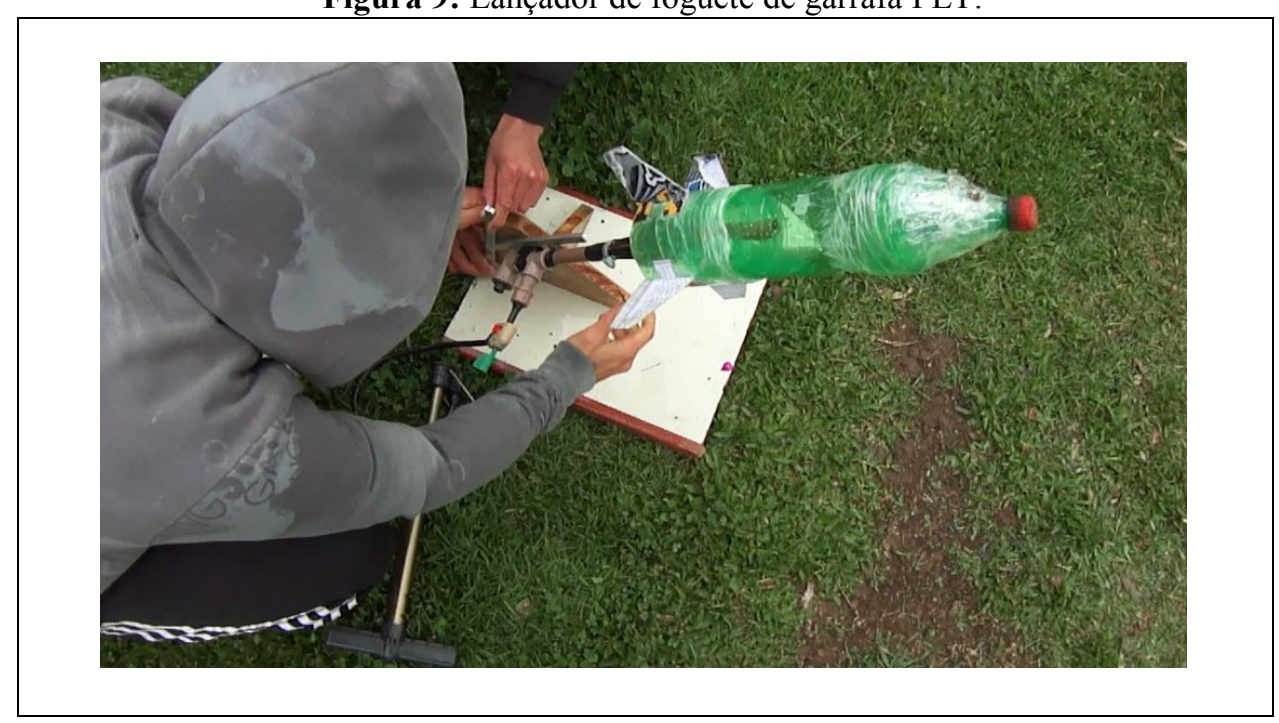

Fonte: a pesquisa.

${ }^{3}$ Disponível em: http://www.youtube.com/watch?v=ilcXnNSu-wo. Acesso em: 20 de junho de 2013. 
Ao término da construção do que os estudantes passaram a chamar de "foguete", acompanhados pelo professor/pesquisador, o grupo realizou três lançamentos com distintas variações de ângulo $\left(30^{\circ}, 40^{\circ}, 45^{\circ}, 50^{\circ}, 60^{\circ}, 70^{\circ}\right.$ e $\left.80^{\circ}\right)$, utilizando sempre a mesma quantidade de água e mesma pressão. Após os três lançamentos, para cada medida de ângulo, era feita uma média com os valores obtidos nos lançamentos.

Durante os lançamentos, os alunos foram percebendo que, com o ângulo de lançamento de $45^{\circ}$ o projétil atingia a maior distância. Já com um ângulo maior que $45^{\circ}$, o projétil atingia uma altura maior, mas diminuía a distância e, com um ângulo de lançamento menor que $45^{\circ}$, diminuía a altura e a distância em relação ao lançamento com um ângulo de $45^{\circ}$, evidenciando que o grupo estava, de fato se apropriando do que ocorria em cada variação do ângulo de lançamento.

Após, estas primeiras evidências, os integrantes do grupo apresentaram cálculos que consideraram relevantes utilizando as equações que haviam estudado e os dados coletados referentes ao lançamento com um ângulo de $45^{\circ}$, referente a velocidade inicial em relação ao eixo x e y, como pode ser observado na Figura 10.

Figura 10: Cálculos de velocidade do projétil nos eixos x e y.

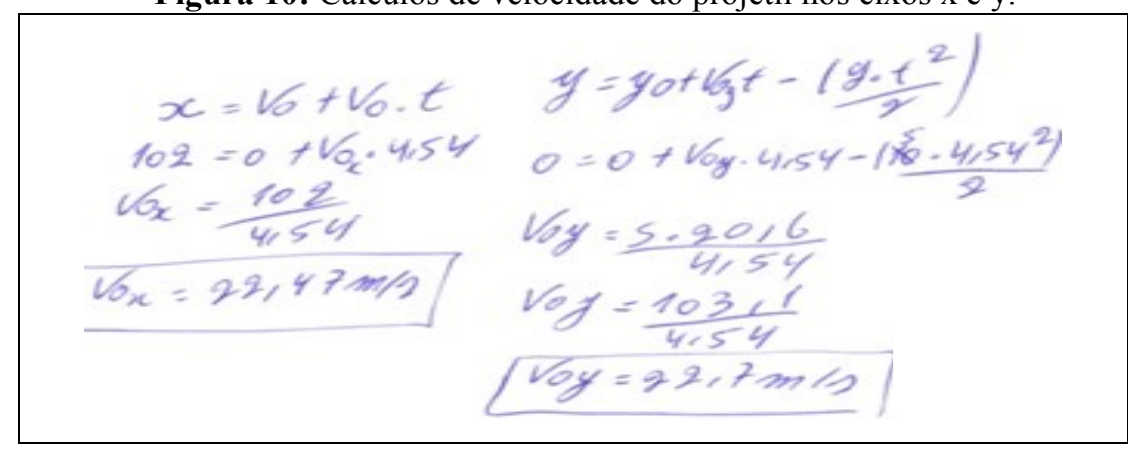

Fonte: a pesquisa.

Com as velocidades em relação ao eixo x e y calculadas e com a equação referente ao módulo do vetor velocidade e do alcance máximo, os estudantes encontram como velocidade inicial do projétil $v_{o}=31,94 \mathrm{~m} / \mathrm{s}^{2}$. Na Figura 11, pode-se observar o desenvolvimento desses cálculos pelos estudantes.

Figura 11: Cálculos de velocidade inicial do projétil.

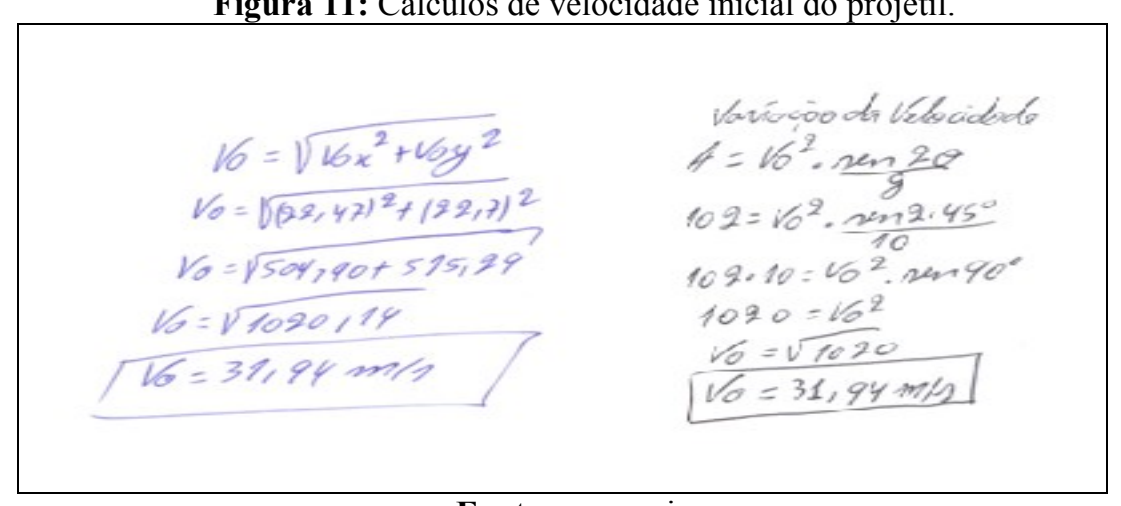

Fonte: a pesquisa. 
Observa-se que, por meio de distintas relações, o grupo chegou ao mesmo valor de $31,94 \mathrm{~m} / \mathrm{s}$ para a velocidade inicial do projétil em relação aos eixos x e y, o que deu evidências de que os cálculos foram realizados de forma correta. Salienta-se, também, que o grupo teve auxílio do professor de Física, o qual os orientou sobre as atividades e, com o material disponibilizado sobre o tema pelo professor/pesquisador os estudantes não apresentaram maiores dificuldades. Na sequência, o grupo apresentou o cálculo referente à altura máxima que o projétil poderia alcançar, chegando a uma altura de 25,71 m sob um ângulo de lançamento de $45^{\circ}$.

Outra atividade desenvolvida refere-se ao tempo para o projétil de garrafa PET alcançar a altura máxima e o tempo total de sua trajetória. Embora os estudantes tivessem conhecimento desses tempos, a partir dos dados experimentais obtidos por meio de filmagem cronometrada, optaram, também, por calculá-los utilizando as equações da Física, já retomadas pelo grupo. Cabe salientar, aqui, que esse procedimento foi adotado pelo grupo para confrontar os valores encontrados através de cálculos com os dados experimentais obtidos durante os testes. Assim, teriam como confirmar, ou não, os dados coletados, além de aprofundar conhecimentos sobre um lançamento oblíquo e as possíveis diferenças entre dados experimentais e dados retirados através de cálculos matemáticos. Os cálculos apresentados pelos estudantes podem ser visualizados na Figura 12.

Figura 12: Cálculo referente ao tempo total e o tempo para alcançar a altura máxima.

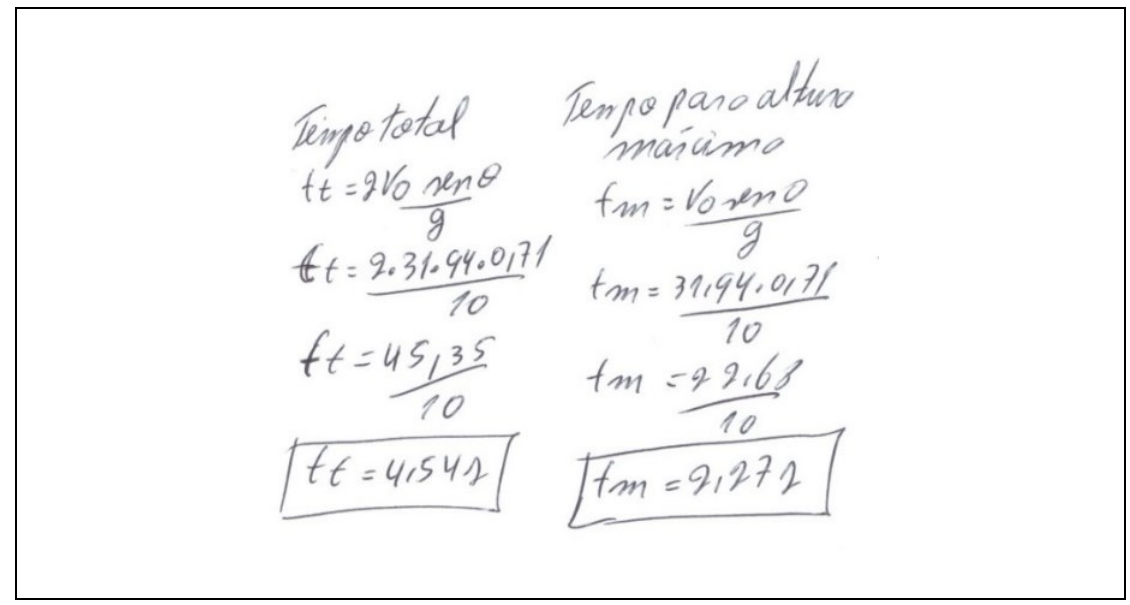

Fonte: a pesquisa.

O desenvolvimento dessas atividades permitiu aos estudantes analisarem e confrontarem diferentes abordagens a uma mesma situação, relacionando conhecimentos matemáticos sobre funções afim e quadrática com conhecimentos sobre movimento retilíneo uniforme e uniformemente variado. Os dados obtidos utilizando elementos da Matemática, da Física e os dados experimentais foram confrontados e analisados mostrando o comportamento do projétil durante o lançamento. Dessa forma, os estudantes puderam retomar e aprofundar 
noções e conceitos dessas duas áreas, discutir as relações existentes e interpretá-las frente a uma situação concreta vivenciada, ampliando seus conhecimentos sobre a questão.

Dando sequência ao projeto, o grupo iniciou as atividades relacionadas ao uso do software Modellus, conforme tinha sido planejado. Os estudantes já haviam estudado e visto modelos criados no software nos materiais disponibilizados pelo professor no grupo do Facebook (tutoriais com exemplos práticos e explicações das principais ferramentas do software). Porém, nas primeiras atividades com o Modellus, consideraram sua utilização complexa, demonstrando pouco interesse em utilizá-lo. Como alternativa o professor sugeriu a utilização do software Excel.

Assim, após uma familiarização com o Excel discussões e ensaios de como o mesmo poderia ser utilizado para modelar as atividades que foram desenvolvidas e a possibilidade de fazer comparações entre o modelo criado no programa e o realizado com lápis e papel, os estudantes assumiram a utilização do software. Em seguida o grupo se reuniu no laboratório de informática da escola para iniciar o trabalho com o Excel a partir dos dados coletados experimentalmente. Foram, inicialmente, construídos os gráficos referentes aos dois lançamentos (catapulta e garrafa PET), em destaque na Figura 13.

Figura 13: Exemplo de gráficos construídos no Excel.

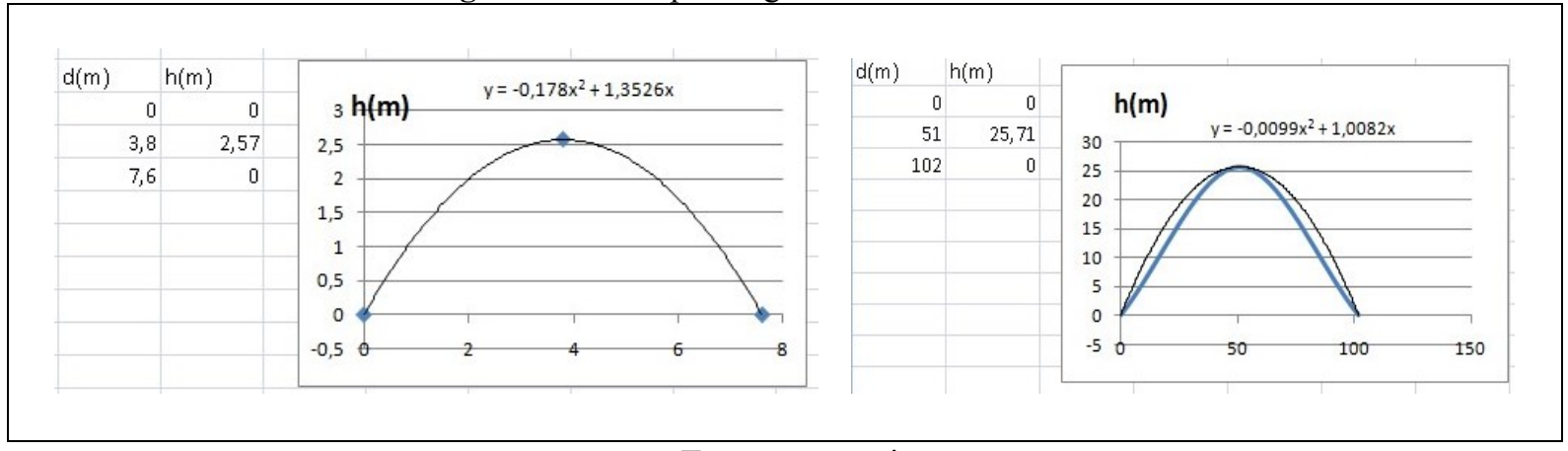

Fonte: a pesquisa

$\mathrm{Na}$ figura, o primeiro gráfico representa um dos modelos (distância pela altura) referente ao experimento com a catapulta e o segundo, o lançamento do projétil de garrafa PET com um ângulo de $45^{\circ}$, também com a variação distância pela altura. Nesse segundo gráfico, além de utilizarem a ferramenta "linha de tendência" para a construção e encontrar o modelo matemático que representava o movimento, também foi utilizada a possibilidade de construção por “dispersão", a qual faz uma aproximação entre os pontos no gráfico.

Observando-se os modelos encontrados e comparando-os com os modelos anteriormente apresentados, é possível perceber que ocorreram pequenas variações nos resultados finais. Como exemplo dessas variações, pode-se apresentar a função encontrada através de cálculos utilizando equações já conhecidas com os modelos criados pelo Excel: 
$y=-0,17 x^{2}+1,29 x$ (cálculo com lápis e papel) e $y=-0,178 x^{2}+1,35 x$ (Excel). Como conclusão, os estudantes consideraram que ocorreu uma boa aproximação entre os dois modelos.

Nessa atividade com o Excel, entende-se que se encontra fortemente a presença da Modelagem Matemática, considerando as ideias propostas por Bassanesi (2002), pois os estudantes, a partir dos dados experimentais tiveram a oportunidade de, com o auxílio do software, gerar um modelo que representava a situação estudada, sendo que, através dos ajustes nas curvas de tendência, foi possível simular e fazer uma aproximação da situação real do lançamento. Os estudantes puderam confrontar, assim, os dados experimentais, a partir da utilização do Excel, com os dados encontrados através do uso de equações advindas da Matemática e da Física. Dessa maneira, o grupo pôde organizar dados, fazer abstrações, confirmar ou não suas conjecturas e hipóteses, buscando simplificar o problema relacionado ao lançamento do projétil, além de chegaram a uma solução para o problema, o qual foi validado através do confronto de diferentes informações recolhidas e construídas pelo grupo.

Considera-se que o trabalho com o software Excel foi uma boa oportunidade dos estudantes se familiarizarem com elementos da área tecnológica, presentes no cotidiano e no mundo do trabalho. A decisão de trabalhar com o Excel, abandonando a ideia inicial de trabalho com o Modellus, foi adequada pois além de possibilitar aos estudantes tomarem uma decisão quanto a ferramenta a ser utilizada, assumindo como responsabilidade sua a tarefa, permitiu o trabalho com um software amplamente utilizado em distintas áreas e situações.

Como atividades de finalização, o grupo se focou na elaboração do trabalho escrito final (relatório do projeto) e do material a ser apresentado aos demais colegas, o que ocorreu em seguida.

A Figura 14 apresenta um dos estudantes explicando e representando o lançamento realizado com a catapulta envolvendo as grandezas distância e altura.

Figura 14: Estudante demonstrando um dos modelos matemáticos.

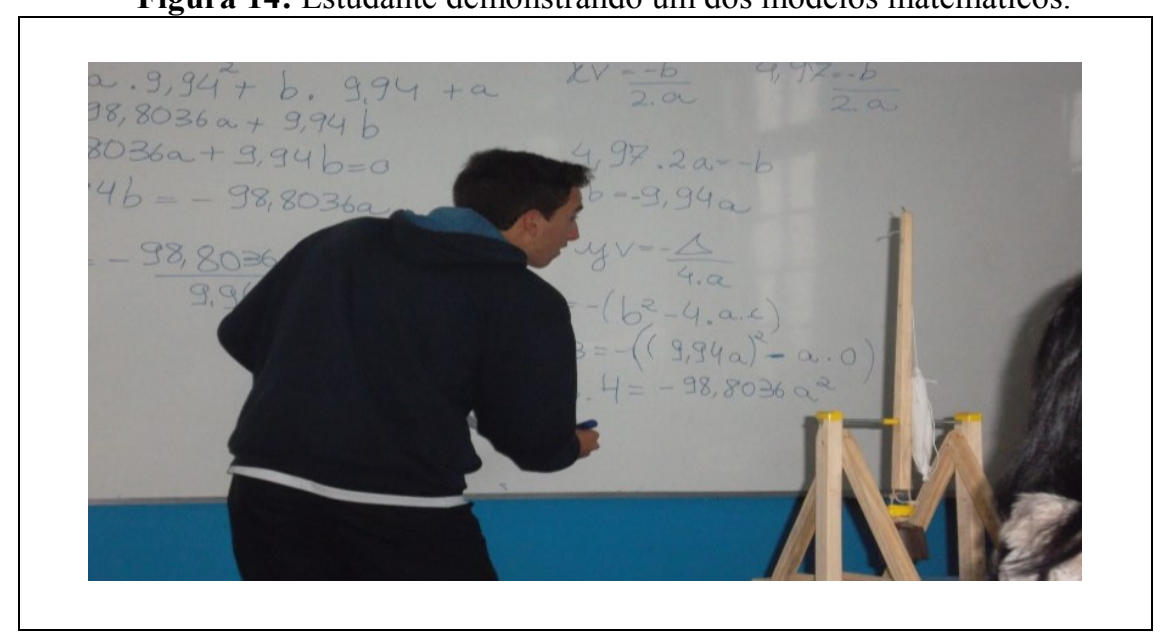

Fonte: a pesquisa. 
Ao longo da apresentação do grupo, frequentemente, os demais estudantes questionavam sobre as operações realizadas evidenciando, por um lado interesse e atenção no que estava sendo apresentado e, por outro, dificuldades em acompanhar o processo matemático desenvolvido pelo grupo. Nesses momentos, o professor/pesquisador fez intervenções, retomando aspectos relacionados ao trabalho com funções de primeiro e segundo graus. .

Após o final da apresentação de todos os projetos dos grupos, foi possível retomar aspectos das atividades desenvolvidas pelo Grupo-A. As principais foram relacionadas a lei de formação de uma função de primeiro e segundo graus, domínio, conjunto imagem, análise gráfica e pontos de máximo e mínimo, considerando, também, o uso do Excel.

Esse trabalho de retomada do conteúdo de Funções foi todo realizado a partir da utilização dos dados experimentais obtidos pelo Grupo-A nos lançamentos com a catapulta e com o lançador de foguete de garrafa PET. Quando da utilização do Excel para o estudo e análise dos diferentes lançamentos com toda a turma do $3^{\circ}$ ano, os estudantes trabalharam em duplas, auxiliados pelo professor/pesquisador e pelos integrantes do Grupo-A. Assim foram criados gráficos e modelos matemáticos que descreviam o movimento realizado pelos projéteis. Salienta-se que também foram realizados cálculos utilizando os modelos já existentes, bem como a construção de gráficos utilizando lápis e papel, buscando que os estudantes também desenvolvessem ou retomassem essas construções. Novamente, os resultados nos diferentes processos foram confrontados e analisados e, posteriormente, discutidos em sala de aula.

\section{Considerações Finais}

O foco do projeto desenvolvido pelo Grupo-A envolveu aspectos relacionados a Física e Matemática, partindo da curiosidade e interesse dos estudantes sobre o lançamento de projéteis aliada a percepção que os próprios estudantes tinham de que não haviam "aprendido" sobre o tema quando estudado em série anterior. Diferentemente da quase totalidade dos demais projetos desenvolvidos pela turma, o tema remetia ao universo da Física e da Matemática.

Como foi um projeto que envolvia conhecimentos de Funções Afim e Quadrática, Movimento Retilíneo Uniforme e Uniformemente Variado e do Lançamento Oblíquo parte das atividades desenvolvidas pelo grupo foram utilizadas, posteriormente, com toda a turma, para a retomada e aprofundamento de conteúdos relacionados a Funções e suas aplicações. 
No que se refere à Modelagem Matemática, considera-se que elementos da mesma foram utilizados durante o trabalho, uma vez que o grupo gerou um expressivo conjunto de dados obtidos de forma experimental, utilizando-os para aproximações a modelos já existentes, utilizando lápis e papel, bem como para modelar a situação estudada utilizando o Excel, buscando soluções para os problemas que surgiram durante os trabalhos. Assim, cálculos foram confrontados e avaliados, hipóteses foram verificadas e soluções que não atendiam ao problema em questão puderam ser descartadas.

Além dos conteúdos da Matemática, o trabalho por Projetos possibilitou, também, que os estudantes compreendessem assuntos presentes no cotidiano, aproximando os conteúdos matemáticos com situações da vida social, mostrando, assim, que a Matemática não se separa das situações em que os alunos estão inseridos. Sendo que, nessa investigação ligada a um tema específico, os estudantes deparam-se com situações matemáticas e físicas as quais necessitaram de soluções, o que permitiu, também, a revisão e o desenvolvimento de conteúdos da Matemática e da Física.

Considera-se que, independente do conhecimento matemático produzido, os Projetos de Trabalho desenvolvidos na turma 302, e particularmente o projeto aqui apresentado, se constituíram em uma possibilidade de modificar o papel do estudante e do professor, possibilitando aos estudantes tornarem-se sujeitos atuantes, participativos, comprometidos com a elaboração de um conhecimento que não é só individual, mas de todo um grupo. $\mathrm{O}$ professor, assumindo um papel de mediador, incentivador e colaborador no processo, teve, a oportunidade de desenvolver conhecimentos referentes a sua prática profissional.

\section{Referências}

BASSANEZI, Rodney Carlos. Ensino-aprendizagem com Modelagem Matemática: uma nova estratégia. São Paulo: Editora Contexto, 2002.

BOGDAN, Roberto C. e BIKLEN, Sari Knopp. Investigação Qualitativa em Educação: uma introdução à teoria e aos métodos. Portugal: Porto Editora, 1994.

BRASIL. Ministério da Educação (MEC). Ciências da Natureza, Matemática e suas Tecnologias/ Secretaria da Educação Básica. Orientações Curriculares para o Ensino Médio. Brasília: MEC/ SEF, 2006, v.2.

COLL,César. Psicologia e Currículo. São Paulo: Ática, 1996.

GROENWALD, Claudia Lisete Oliveira; SILVA, Carmen Kaiber da; MORA, Castor David. Perspectivas em Educação Matemática. 2004. Disponível em: 
$<$ http://www.periodicos.ulbra.br/index.php/acta/article/viewFile/129/117>. Acesso em: 07 maio 2014.

HERNÁNDEZ, Fernando; VENTURA, Montserrat. A Organização do Currículo por Projetos de Trabalho. $5^{\circ}$ ed. Porto Alegre: Artes Médicas, 1998.

HERNÁNDEZ, Fernando. Transgressão e mudança na educação: os projetos de trabalho. Porto Alegre: Artmed,1998.

MALHEIROS, Ana Paula dos Santos. Educação Matemática online: a elaboração de projetos de Modelagem Matemática. 2008. Tese (Doutorado em Educação Matemática) Instituto de Geociências e Ciências Exatas (IGCE), Universidade Estadual Paulista (UNESP), Rio Claro/SP, 2008.

Algumas interseções entre projetos e modelagem no contexto da Educação Matemática. Acta Scientiae: Revista de Ensino de Ciências e Matemática. V. 13, N. 1 (2011). P. 71-86.

MORA, Castor David. Aprendizaje y enseñanza: projectos y estratégias para uma educación matemática del futuro. LaPaz, Bolivia: Campo Iris, 2003.

RIPARDO, Ronaldo Barros; OLIVEIRA, Marcelo de Sousa; SILVA, Francisco Hermes da. Modelagem Matemática e Pedagogia de Projetos: aspectos comuns. ALEXANDRIA Revista de Educação em Ciência e Tecnologia, v.2, n.2, p.87-116, jul. 2009. 